\title{
Toward multiscale modeling of thin-film growth processes using SLKMC - ERRATUM
}

\author{
Shree Ram Acharya and Talat S. Rahman \\ doi: 10.1557/jmr.2018.44, Published by Materials Research Society with Cambridge University \\ Press, 28 March 2018.
}

The paper by Acharya and Rahman ${ }^{1}$ was inadvertently published in Volume 33, Issue 6 of Journal of Materials Research. The article is part of the Journal of Materials Research Focus Issue on Advanced Atomistic Algorithms in Materials Science and is referenced as such in the introduction to that issue. ${ }^{2}$

The publishers apologize for the error.

\section{REFERENCES}

1. S.R. Archarya and T.S. Rahman: Toward multiscale modeling of thin-film growth processes using SLKMC. J. Mater. Res. 33, 709-719 (2018). doi: 10.1557/jmr.2018.44.

2. E. Martinez, D. Perz, V. Gavani, and S. Kenny: Introduction. J. Mater. Res. 33, 773-776 (2018). doi: 10.1557/jmr.2018.69. 